\title{
SUCESSO E FRACASSO DOS BOLSISTAS DO PROGRAMA CONEXÕES DE SABERES DA UFSC
}

\author{
Gilson Braviano \\ Universidade Federal de Santa Catarina \\ gilson@cce.ufsc.br
}

Erro! Fonte de referência não encontrada.

Este artigo apresenta indicadores quantitativos relativos à trajetória dos alunos de origem popular da UFSC que integraram o Programa Conexões de Saberes entre 2006 e 2011. Objetiva-se, a partir dos dados obtidos, descrever o grau de sucesso da trajetória acadêmica dos ex-bolsistas e oferecer um panorama que identifique em que medida o Programa Conexões de Saberes contribuiu para o sucesso dos acadêmicos que tiveram a oportunidade de vivenciar esta experiência na UFSC. Para tanto, utilizam-se informações como os índices de aproveitamento dos alunos, número de reprovações, tempo utilizado para concluir o curso, publicações realizadas e tempo de permanência no Programa, considerando os dados de 2012 como data base para a análise. Os resultados apontam um índice de $87,02 \%$ de sucesso. O fracasso, contemplando os casos de desistência e jubilamento, representa $10,68 \%$ do total de alunos, existindo, ainda, 2,30\% dos ex-bolsistas em situação de trancamento.

Palavras-chave: Programa Conexões de Saberes. Sucesso e Fracasso. Origem Popular.

\section{SUCCESS AND FAILURE OF THE STUDENTS IN PROGRAMA CONEXÕES DE SABERES AT UFSC}

\begin{abstract}
This paper presents quantitative indicators associated to students of popular origin of UFSC who joined the Programa Conexões de Saberes between 2006 and 2011. Our intention is, from the data obtained, describe the degree of success of the academic trajectory of alumni and provide an overview that identifies the extent to which Programa Conexões de Saberes contributed to the success of students who had the opportunity to live this experience at UFSC. For this, we use information such as the rates of student achievement, number of failures, time used to complete the course, posts held and length of stay in the program, considering the 2012 data as the baseline for the analysis. The results show that $87.02 \%$ of success rate is achieved. The failure, considering the case of revocation and retired, represent $10.68 \%$ of total students. Also exists $2.30 \%$ of students that locked the course.
\end{abstract}

Keywords: Programa Conexões de Saberes. Success and Failure. Popular Origin.

\section{ÉXITO Y FRACASO DE LOS ALUMNOS DEL PROGRAMA CONEXÕES DE SABERES DE LA UFSC}

\section{Resumen}

En este artículo se presentan indicadores cuantitativos sobre la trayectoria de estudiantes de origen popular de la UFSC que integráran el Programa Conexões de Saberes entre 2006 y 2011. El objetivo es, a partir de los datos, describir el grado de éxito de la carrera académica de los alumnos y proporcionar una visión general que permita identificar en qué medida el Programa Conexões de Saberes ha contribuido al éxito de los estudiantes que tuvieron la oportunidad de experimentar esta experiencia en UFSC. Por lo tanto, se utilizan informaciones tales como el uso de índices académicos, el número de fracasos, el tiempo utilizado para completar el curso, las publicaciones llevadas a cabo y el tiempo de permanencia en el programa, teniendo en cuenta los datos de 2012 como la línea de base para el análisis. Los resultados muestran una tasa de éxito de $87,02 \%$. El fracaso, teniendo en cuenta los casos de cancelación y jubilamento, representan 10,68\% del número total de estudiantes. Hay también 2,30\% de los alumnos en situación de bloqueo.

Palavras clave: Programa Conexões de Saberes. Éxito y fracaso. Origen popular. 


\section{INTRODUÇÃO}

No primeiro semestre de 2006, um termo novo passou a integrar o vocabulário das pessoas ligadas às Pró-Reitorias de Extensão no Brasil: aluno de origem popular. O significado deste termo, do qual todas as palavras eram conhecidas, mas não o sentido preciso da expressão, gerou dúvidas e surgiu, inclusive, o questionamento se a partir daquele momento o aluno dito carente passaria a ser denominado aluno de origem popular.

O referido termo passou a integrar o rol de expressões correntes em diversos setores das Universidades Brasileiras onde o Programa Conexões de Saberes foi implementado. No caso da UFSC, os critérios que caracterizavam um estudante de origem popular foram sendo assimilados aos poucos, à medida que o Ministério da Educação, através da extinta SECAD - Secretaria de Educação Continuada, Alfabetização e Diversidade -, lapidava um documento denominado 'Texto de Referência do Programa' e que se ampliavam os contatos com outros atores das demais instituições envolvidas com este Programa.

O grande diferencial do Programa Conexões de Saberes estava na superação da concepção de assistencialismo estudantil, passando-se a considerar, além da condição sócioeconômica propriamente dita, os valores e saberes dos alunos provenientes de comunidades populares. Oriundos dessas comunidades, tais estudantes vivenciaram suas formações em escolas públicas e representam a primeira geração de suas famílias a ter acesso ao ensino superior.

O Programa Conexões de Saberes foi implantado, em 2006, na UFSC e, com o perfil acima descrito, 131 alunos de origem popular passaram por ele. Seminários locais, regionais e nacionais ocorreram por todo o país e, em dezembro de 2011, este Programa migrou para o modelo PET - Programa de Educação Tutorial - em todo o país.

O entendimento do que seria um aluno de origem popular foi essencial neste período, já que os bolsistas a serem inseridos no Programa Conexões de Saberes (e, agora, no PET Conexões de Saberes) deveriam (e devem) ser de origem popular. No transcorrer dos últimos anos, uma reflexão mais ampla apontou para a necessidade de dar visibilidade a esses estudantes, que superaram uma série de barreiras e conseguiram ser aprovados em uma Instituição Pública de Ensino Superior. Não apenas isso, eles iniciaram uma trajetória diferenciada daquela vivenciada pelas outras pessoas do seu contexto familiar, pois pertenciam eles à primeira geração da sua família a ter acesso ao ensino superior. Os desafios não pararam aí, já que esses acadêmicos vivenciariam ainda o desafio de se transformarem sem quebrar o elo com sua origem, sem negála, sem desvalorizá-la. 
Braviano e Nodari (2007, p. 2), apontaram as três metas gerais do Programa Conexões de Saberes na UFSC, até aquele momento: "ampliar, para os bolsistas do programa, condições de permanência com qualidade nos seus cursos; sensibilizar os diferentes atores que integram a UFSC sobre a importância da democratização do acesso e permanência dos jovens de origem popular na instituição de ensino; e contrapor o processo de favelização ocorrido na comunidade da Serrinha, aproveitando as competências e capacidades dos seus moradores". Esta última meta tomou uma proporção maior que as demais, sendo que os bolsistas focaram a maior parte das suas atividades em ações extensionistas como produzir e introduzir plantas (frutíferas e ornamentais, para a horta comunitária) com potencial para reflorestar áreas degradadas; realizar atividades de educação ambiental; reativar a trilha de acesso à comunidade; criar biblioteca comunitária na comunidade; colaborar em atividades esportivas e de lazer; orientar a higiene dentária na comunidade, entre outras.

Em 2009, ocorreu uma transformação na linha norteadora da diretriz pedagógica do Programa na UFSC e seu impacto enquanto tecnologia social para a transformação social e enfrentamento dos problemas dos alunos de origem popular. Braviano et. al (2009, p. 5) explicitam que

o foco dos nossos esforços no desenvolvimento do Programa Conexões da UFSC em 2008/2009 se encontra na formação dos bolsistas. [...] A permanência dos acadêmicos de origem popular em Instituições de Ensino Superior não é função exclusiva das ações de assistência socioeconômica, mas também de ações de natureza sócio-pedagógica que reconheçam e valorizem a trajetória destes estudantes, possibilitando a formação no sentido de complexo processo de transformação e produção cultural.

Dentro deste contexto dinâmico, o presente artigo busca descrever em que medida o Programa Conexões de Saberes contribuiu para o sucesso dos acadêmicos que tiveram a oportunidade de vivenciar esta experiência na UFSC. Tal análise é realizada à luz da trajetória dos ex-bolsistas, seus índices de aproveitamento, número de reprovações, tempo utilizado para concluir o curso, publicações realizadas e tempo de permanência no Programa.

\section{MATERIAIS E MÉTODOS}

Este texto se pauta em informações da trajetória acadêmica de cada um dos 131 alunos de origem popular da UFSC que integraram o Programa Conexões de Saberes entre 2006 e 2011. Os dados, de origem documental, foram obtidos com o apoio da Pró-Reitoria de Graduação, sendo utilizado 2012 como ano base para descrever um panorama quantitativo sobre o grau de sucesso 
dos ex-bolsistas em relação a sua trajetória acadêmica a partir do momento que ingressaram no Programa. Optou-se, neste artigo, por considerar sucesso toda trajetória que conduziu um aluno à conclusão do curso ou permitiu que, mesmo não tendo concluído ainda, ele não o tivesse abandonado. Assim, o fracasso se configura nas situações de desistência (onde não ouve retorno ou transferência para outro curso), abandono ou jubilamento. Os acadêmicos em situação de trancamento serão tratados sempre separadamente.

\section{RESULTADOS E ANÁLISE}

O Quadro 1 apresenta um panorama global da situação dos ex-bolsistas do Programa Conexões de Saberes da UFSC, no final de 2012. Dos 131 alunos 49 se formaram e 65 ainda estavam cursando a graduação, sendo que, destes últimos, oito mudaram de curso. Desta forma, temos configurado $87,02 \%$ de sucesso, conforme ilustra a Figura 1. O fracasso, contemplando os casos de desistência e jubilamento, representa 10,68\% do total de alunos. Tem-se, ainda, 2,30\% dos ex-bolsistas em situação de trancamento.

\begin{tabular}{|c|c|c|c|c|c|c|c|}
\hline \multirow{3}{*}{ Ano } & \multirow{3}{*}{$\begin{array}{l}\text { Ingressantes } \\
\text { no Programa }\end{array}$} & \multirow{3}{*}{$\begin{array}{l}\text { Permanência } \\
\text { média (em } \\
\text { meses) }\end{array}$} & \multicolumn{5}{|c|}{ Situação atual em relação ao curso } \\
\hline & & & \multicolumn{2}{|c|}{ Sucesso } & \multirow{2}{*}{ Trancamento } & \multicolumn{2}{|c|}{ Fracasso } \\
\hline & & & Formado & Cursando & & Abandono & Jubilado \\
\hline 2006 & 27 & 16,78 & 22 & 2 & 2 & 1 & 0 \\
\hline 2007 & 29 & 14,66 & 18 & 4 & 1 & 6 & 0 \\
\hline 2008 & 17 & 15,29 & 4 & 11 & 0 & 2 & 0 \\
\hline 2009 & 20 & 14,80 & 5 & 11 & 0 & 3 & 1 \\
\hline 2010 & 38 & $7,95^{*}$ & 0 & 37 & 0 & 1 & 0 \\
\hline \multirow{3}{*}{ Total } & 131 & \multirow{3}{*}{ - } & 49 & 65 & 3 & 13 & 1 \\
\hline & \multirow{2}{*}{$100 \%$} & & $37,40 \%$ & $49,62 \%$ & \multirow{2}{*}{$2,30 \%$} & $9,92 \%$ & $0,76 \%$ \\
\hline & & & \multicolumn{2}{|c|}{87,02} & & \multicolumn{2}{|c|}{10,68} \\
\hline
\end{tabular}

* Este período médio leva em conta a permanência dos ex-bolsistas apenas até março de 2011, desconsiderando que 17 deles continuaram atuando no Programa Conexões de Saberes, na modalidade PET - Programa de Educação Tutorial.

Quadro 1 - Situação, em 2012, dos ex-bolsistas do Programa Conexões de Saberes da UFSC, pelo ano de ingresso e período de permanência

Fonte: Elaborado pelo autor, 2015.

Este primeiro panorama indica um resultado positivo e será aprofundado na sequência, para que se possa estabelecer em que medida a inserção dos alunos no Programa impactou no seu sucesso acadêmico e em que medida não se conseguiu garantir a permanência nos cursos. 


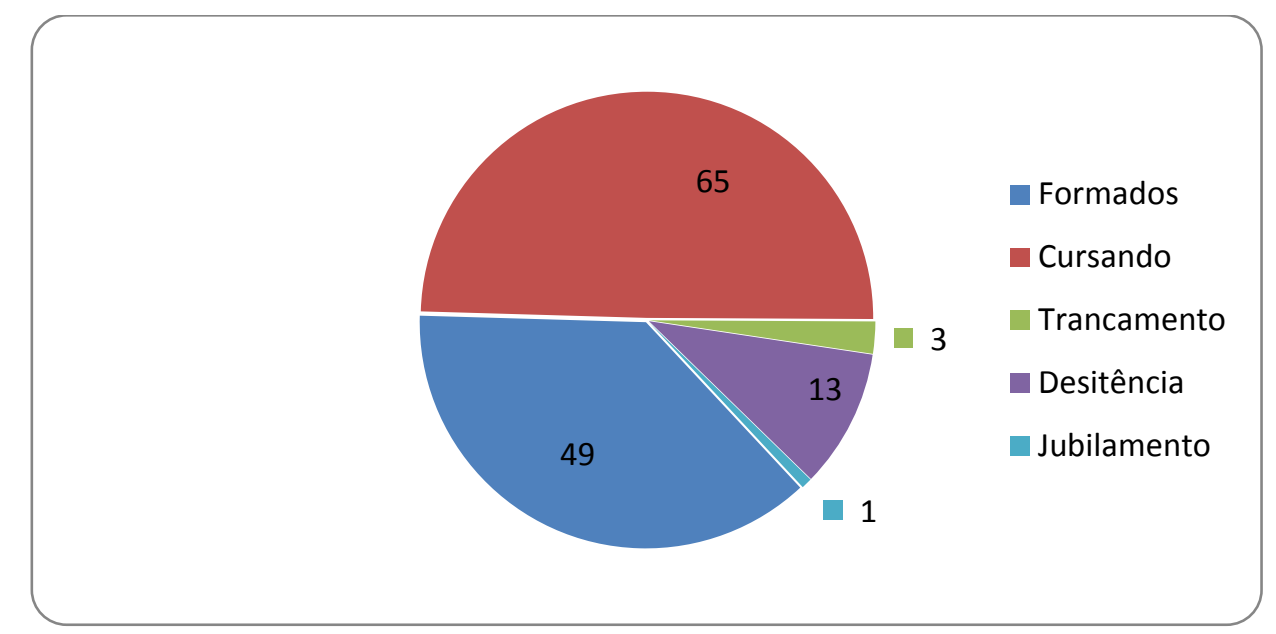

Figura 1 - Situação, em 2012, dos 131 ex-bolsistas do Programa Conexões de Saberes da UFSC Fonte: Elaborado pelo autor, 2015.

\section{Alunos que concluíram o curso até 2012}

Dos 49 alunos que já se formaram, 22 ingressaram no Programa Conexões de Saberes em 2006, 18 em 2007, quatro em 2008, cinco em 2009 e nenhum em 2010, conforme indica o Quadro 1. Esta sequência de quantidades não gera surpresa, já que uma das metas do Programa foi integrar acadêmicos em fases iniciais dos cursos, portanto grande parte daqueles que entraram após 2008 ainda estavam regularmente matriculados e cursando disciplinas em 2012.

Através de informações fornecidas pela Pró-Reitoria de Graduação, obteve-se a média dos IAAs - Índice de Aproveitamento Acumulado - dos ex-bolsistas formados, que é 8,13. Este índice corresponde à média ponderada das notas de todas as disciplinas cursadas, usando como peso a carga horária. Este indicador é positivo, levando em conta que a nota mínima para aprovação em qualquer disciplina, em uma escala de zero a dez, é 6,0 e que o desvio padrão foi 0,81. Oito desses alunos (16,33\%) alcançaram um IAA final de excelência, ou seja, superior a 9,0. Quatro outros chegaram muito próximos deste valor, com resultados finais 8,90; 8,96; 8,98 e 8,99 .

A média de tempo que estes alunos levaram para concluir seus cursos foi de 10,43 semestres, ou seja, pouco mais de cinco anos. Estando, a maioria deles, matriculados em cursos de quatro ou cinco anos, percebe-se que nem todos conseguiram concluir a formação superior no prazo mínimo previsto. 


\section{Alunos regularmente matriculados em 2012}

Dos 131 alunos que participaram do Programa Conexões de Saberes da UFSC, 65 ainda mantinham sua matrícula em 2012, porém três trancaram o curso. Os outros 62 estavam cursando disciplinas. Apresenta-se, na sequência, um panorama da trajetória desses ex-bolsistas, baseada na quantidade de disciplinas em que se matricularam, na quantidade de disciplinas em que não obtiveram aprovação, no número de semestres cursados e no seu IAA.

Dentre os alunos que ingressaram no Programa em 2006, dois ainda estavam com matrícula regular em 2012, sendo que um deles havia mudado de curso recentemente e o outro estaria em vias de concluí-lo. Este segundo acadêmico foi aprovado em todas as disciplinas em que se matricularam durante os dez semestres de permanência no curso e seu IAA atinge 8,57.

Dentre os alunos que ingressaram no Programa em 2007, cinco ainda estavam com matrícula regular em 2012, sendo que dois deles estavam em vias de conclusão, um com $\mathrm{IAA}=8,97$ e outro com IAA $=6,07$, ou seja, com aproveitamentos bem distintos nas disciplinas. Quanto aos outros três, um reprovou em 15 das 53 vezes em que se matriculou em disciplinas, o segundo reprovou em apenas duas das 34 vezes em que efetuou matrícula. Ambos estão em vias de se formar, tendo permanecido nos cursos 11 e 10 semestres respectivamente. O IAA do primeiro deles é, atualmente, 5,79 (bastante afetado pelas reprovações) e o do segundo aluno atinge 8,76. O quinto aluno mudou de curso.

Dentre os alunos que ingressaram no Programa em 2008, dez ainda estavam com matrícula regular em 2012, com média de oito semestres cursados. Ocorre, neste grupo, uma variedade de situações, algumas descritas sucintamente a seguir. Três mudaram de curso, sendo que um deles conseguiu, durante a sua permanência no Programa, ser aprovado para o mais concorrido curso da UFSC: medicina. Assim, desistiu de enfermagem e iniciou a formação que verdadeiramente desejava fazer. Há um aluno com IAA=1,43, que reprovou em 20 das 25 vezes em que efetuou matrículas, configurando um caso de reprovações por frequência insuficiente. Sua saída do Programa deu-se por essa razão, já que uma das metas do Programa sempre foi destinar bolsas para aqueles que realmente se esforçassem para concluir sua formação.

Dentre os alunos que ingressaram no Programa em 2009 e 2010, 48 ainda estavam com matrícula regular em 2012, portanto com perspectivas reais de conclusão da sua formação em nível superior. Destes, 22 não apresentavam reprovações até o momento da coleta de dados e 11 tiveram, no máximo, três reprovações. 


\section{Alunos que abandonaram o curso ou foram jubilados}

Dos 131 alunos que participaram do Programa Conexões de Saberes da UFSC um foi jubilado após cursar 16 semestres e 13 abandonaram o curso. Destes, apenas um integrou o Programa em 2006, tendo cursado cinco semestres e reprovado em oito das 18 vezes em que efetuou matrículas em disciplinas. Dentre os 29 ex-bolsistas que ingressaram no Programa em 2007 seis abandonaram seus cursos, tendo todos cursado pelo menos cinco semestres. Um desses casos chama a atenção: uma aluna que no décimo semestre abandonou o curso, tendo IAA=9,04. Até o presente não se tem informações sobre a razão desta decisão. Dentre aqueles 17 que ingressaram no Programa em 2008 dois não concluíram o curso e o abandonaram, tendo todos reprovado em pelo menos $50 \%$ das disciplinas que cursaram. Um deles, casado, sempre comentava sua dificuldade financeira para manter estudos e família. Dentre aqueles 58 que ingressaram no Programa em 2009 e 2010 quatro abandonaram o curso, sendo que apenas um deles não apresentava rendimento muito ruim, com quatro reprovações nas quinze matrículas que cursou.

A coordenação do Programa Conexões de Saberes sempre buscou acompanhar a trajetória acadêmica dos alunos, estando aberta ao diálogo cada vez que detectava situações de risco quanto ao abandono do curso ou de desempenho insuficiente dos bolsistas. Na tentativa de compreender como 10,68\% dos ex-bolsistas não lograram êxito neste contexto, observa-se, no Quadro 1, que cada bolsista atuou, em média, 14 meses no Programa. O desvio padrão associado a esse período médio de permanência é de oito meses, valor extremamente alto, indicando que alguns ex-bolsistas permaneceram muito tempo e outros tiveram passagens extremamente rápidas pelo Programa. A Figura 2 apresenta a distribuição desses períodos, por semestres.

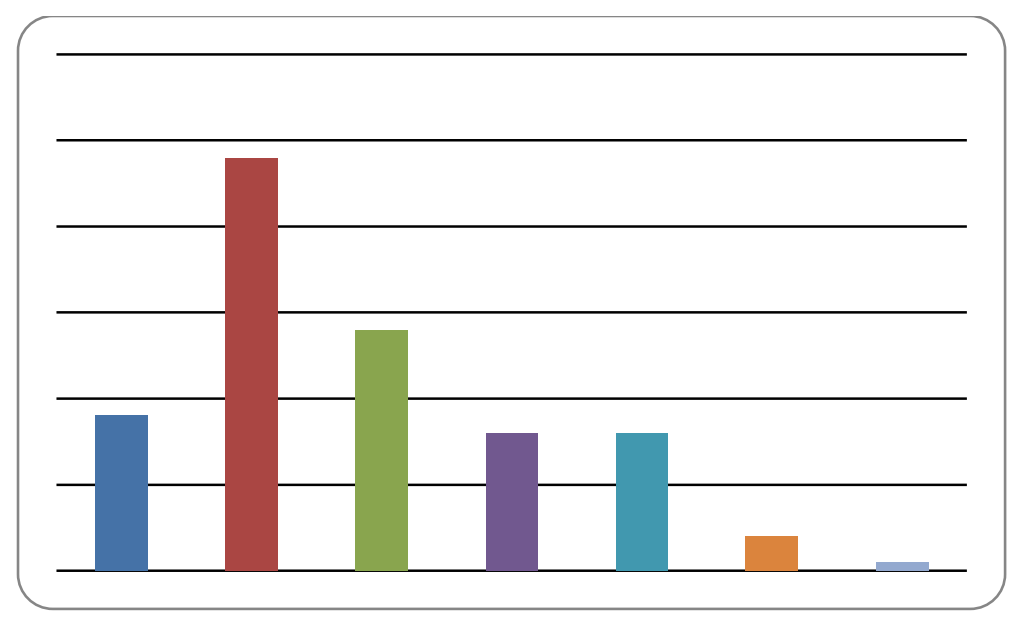

Figura 2 - Número de bolsistas em relação à quantidade máxima de semestres que permaneceram no Programa Fonte: Elaborado pelo autor, 2015. 
Ainda na Figura 2 observa-se que 18 alunos (13,74\% do total de ex-bolsistas) não ultrapassaram os seis meses de permanência no Programa. Neste grupo está o único acadêmico que atuou no Conexões de Saberes e foi jubilado, tendo permanecido exatamente seis meses em atividades. O número de alunos que permaneceu entre sete e doze meses no Programa foi 50. Destes, seis abandonaram seus cursos e dois trancaram a matrícula. Esses dados indicam que mais de 50\% dos bolsistas que integraram o Programa Conexões de Saberes da UFSC não permaneceram mais que um ano (Quadro 2). Em contrapartida, dos 61 alunos que permaneceram em atividades mais que doze meses, apenas cinco não estão categorizados com uma trajetória de sucesso.

\begin{tabular}{|l|c|c|c|}
\hline Tempo de permanência & Sucesso & Fracasso & Trancamento \\
\hline Menos de 1 semestre & 14 & 3 & 0 \\
\hline Entre 1 e 2 semestres & 42 & 6 & 2 \\
\hline Entre 2 e 3 semestres & 24 & 4 & 0 \\
\hline Entre 3 e 4 semestres & 16 & 0 & 0 \\
\hline 4 semestres ou mais & 19 & 1 & 1 \\
\hline
\end{tabular}

Quadro 2 - Ex-bolsistas do Programa Conexões de Saberes da UFSC, por permanência no Programa e sucesso/fracasso acadêmico

Fonte: Elaborado pelo autor, 2015

Não é intenção deste texto estabelecer uma correlação entre a permanência no Programa Conexões de Saberes e o sucesso acadêmico, até porque as razões dos abandonos nem sempre constituem uma situação de fracasso escolar. Este é o caso, por exemplo, de um aluno que optou por abandonar seu curso de Licenciatura em Matemática para seguir a carreira militar de seu pai. No momento da despedida do grupo, este aluno ressaltou a importância que a experiência vivenciada no Programa tinha lhe trazido e afirmou que estava convicto que estava mudando sua trajetória confiante na realização pessoal da nova carreira.

Outro resultado quantitativo interessante no caso da UFSC, é que dos ex-bolsistas que integraram o Programa, dez mudaram de curso. Este percentual de 7,63\% indica que tais alunos repensaram suas trajetórias e buscaram novos horizontes, contrapondo-se àqueles que apenas abandonaram sua formação.

O perfil dos estudantes de origem popular tem suas particularidades, quando comparado ao perfil daqueles alunos que tiveram parte da sua trajetória escolar realizada em instituições privadas ou que provêm de territórios com poucas características populares. Mudam as prioridades na vida desses acadêmicos e muda também a força do impacto de experiências acadêmicas negativas. Esta temática foi o centro de uma pesquisa, apresentada em Braviano et. al 
(2006), onde um dos objetivos foi identificar expressões associadas a sofrimento e dor na vida desses bolsistas, gerando os seguintes termos mais frequentes: perda, separação, morte, acidente, preconceito, fome e dificuldade. Tais elementos, que poderiam gerar desmotivação, serviram de mola propulsora e fortaleceram estes acadêmicos no sentido de valorizarem as oportunidades que surgissem.

As trajetórias seguidas por cada estudante são, portanto, ímpares, sendo que alguns transformaram as possibilidades que o Programa Conexões de Saberes ofereceu em elementos decisivos para sua formação enquanto cidadãos e profissionais. Diversas citações neste sentido estão presentes no livro Caminhadas de universitários de origem popular da UFSC, dentre as quais, destaca-se "eu tinha ingressado no programa por causa da bolsa e só depois eu vi a grandiosidade deste projeto" (PERES, 2009, p. 50).

\section{CONSIDERAÇÕES FINAIS}

Escrever este artigo, que configura um texto de fechamento e, ao mesmo tempo, de transição, a respeito de um Programa com a relevância do Conexões de Saberes foi uma tarefa prazerosa, mas, sobretudo, reflexiva. O caráter reflexivo surgiu no momento em que a descrição estatística permitiu vislumbrar em que medida todos os esforços dos seis anos de existência deste Programa na UFSC geraram resultados positivos. O prazer adveio da convicção que tais esforços contribuíram para o sucesso na formação da maioria dos alunos.

Algumas questões, entretanto, surgiram e buscou-se abordá-las através de textos já publicados em congressos e livros, tais como as adaptações feitas no escopo local do Programa, na intenção de ir de encontro às expectativas dos atores deste processo. Observou-se que as publicações científicas, na sua maioria, foram realizadas pela equipe de coordenadores e não pelos bolsistas, que sempre demonstraram maior interesse em utilizar seu tempo para ampliar a formação acadêmica e participar de ações de extensão em comunidades populares.

A tríade extensão-ensino-pesquisa teve, no caso dos ex-bolsistas da UFSC, seu ponto mais frágil exatamente na pesquisa. Contudo nos parece que com a transição para o modelo PET Conexões de Saberes há uma tendência de aproximação dos bolsistas de origem popular com a pesquisa científica. Entre 2011 e 2013, diversas publicações foram realizadas com a participação ativa dos acadêmicos: Silva et. al (2011), Souza et. al (2011), Costa et. al (2011), Honorato et. al (2011), Kegler et. al (2012), Rachadel et. al (2012), Sarvacinski et. al (2012), Damazo et. al (2012), Sarvacinski et. al (2013) e Weiss et. al (2013). No peeríodo 2014-2015 este quantitativo decaiu um 
Sucesso e fracasso dos bolsistas do Programa Conexões de Saberes da UFSC

pouco. Cabe, aqui, destacar os Trabalhos de Conclusão de Curso que foram realizados por exbolsistas do Programa, com temáticas voltadas ao Conexões de Saberes: Calixto (2011), Jesus (2011) e Maciel (2007).

Particularmente, por ter sido o coordenador do Programa na UFSC, durante todo o tempo em que ele funcionou, não sou mais o mesmo; mudei enquanto ser humano. E o reflexo disto na minha vida profissional é impactante. É impensável não levar essa temática para minhas aulas, conversa de corredor com os colegas e meu círculo familiar, até porque eu fui um estudante de origem popular.

Do mesmo modo, retomando a reflexão de Braviano e Bortolini (2014), grande parte dos bolsistas que vivenciaram o Programa por pelo menos um semestre se transformaram e reforçaram sua identidade popular, sabendo como conviver com ela, sem negá-la, mas considerando-a como alicerce e diferencial na sua formação.

\section{REFERÊNCIAS}

BRAVIANO, G.; BORTOLINI, M. H. Z.; ESPINDOLA, C. M.; HEIDRICH, D. N. ; CORTIZO, M. C. Programa Conexões de Saberes da UFSC: caminhada para o enfrentamento dos desafios da inclusão. In: Anais do $4^{\circ} \mathrm{CBEU}$ - Congresso Brasileiro de Extensão Universitária, Dourados, 2009.

BRAViano, G.; BORTOLINI, M. H. Z. Resultados do Programa Conexões de Saberes da UFSC. In: Anais do $6^{\circ} \mathrm{CBEU}$ - Congresso Brasileiro de Extensão Universitária, 2014, Belém, vol. 1, 2014.

.; NODARI, E. S. Atuação do Programa Conexões de Saberes da UFSC na comunidade da Serrinha. Expressa Extensão (UFPel), v. 12, p. 1-8, 2007.

; WOLFF, F. A.; PEREIRA, S. R. V. Conexões de Saberes na UFSC: atividades desenvolvidas no eixo de formação dos bolsistas. In: Anais do $3^{\circ} \mathrm{CBEU}$ - Congresso Brasileiro de Extensão Universitária, Florianópolis, 2006.

CALIXTO, Tatiana R. O programa conexões de saberes e a permanência do estudante de origem popular no ensino superior. Trabalho de Conclusão de Curso (Graduação em Serviço Social), UFSC, 2011. 
COSTA, M. N.; SCHUTZ, I.; KEGLER, A. J. M.; PORTELA, F. D.; BRAVIANO, G. Políticas de permanência na UFSC. In: Anais da $10^{\mathrm{a}}$ SEPEX - Semana de Ensino, Pesquisa e Extensão da UFSC, Florianópolis, 2011.

DAMAZO, N. A.; RACHADEL, M. B.; SARVACINSKI, F. S.; BRAVIANO, G. Direito Universal à Água Potável e ao Saneamento Básico. In: Anais da $11^{a}$ SEPEX - Semana de Ensino, Pesquisa e Extensão da UFSC, Florianópolis, 2012.

HONORATO, S.; PORTELA, F. D.; KEGLER, A. J. M.; BRAVIANO, G. Contribuição das novas tecnologias para a acessibilidade de cegos ao ensino à distância. In: Anais do $5^{\circ}$ CONAHPA - Congresso Nacional de Ambientes Hipermídia para Aprendizagem, Pelotas, 2011.

JESUS. Aralan G. R. Ensino de matemática no curso pré-vestibular da UFSC: o ponto de vista dos alunos. Trabalho de Conclusão de Curso (Graduação em Licenciatura em Matemática), UFSC, 2011.

KEGLER, A. J. M.; SILVA, V. C.; BRAVIANO, G. A importância do desenho para a expressão e representação humana. In: Anais da $11^{a}$ SEPEX - Semana de Ensino, Pesquisa e Extensão da UFSC, Florianópolis, 2012.

MACIEL, Ananda M. Pegadas e (des)caminhos: trajetórias escolares de jovens de origem popular. Trabalho de Conclusão de Curso (Graduação em Pedagogia), UFSC, 2007.

PERES, Fernanda. Minha origem. In: Jailson de Souza e Silva; Jorge Luiz Barbosa; Ana Inês Sousa. (Org.). Caminhadas de Universitários de Origem Popular da UFSC. $1^{a}$ ed., Rio de Janeiro: 2009.

RACHADEL, M. B.; DAMAZO, N. A.; MACHADO, V.; BRAVIANO, G. As ações afirmativas do nível micro ao macro: da inclusão universitária até as missões de paz e ajuda humanitária da ONU. In: Anais da 11 a SEPEX - Semana de Ensino, Pesquisa e Extensão da UFSC, Florianópolis, 2012.

SARVACINSKI, F.; MACHADO, V.; SILVA, V. C.; KEGLER, A. J. M.; BRAVIANO, G.

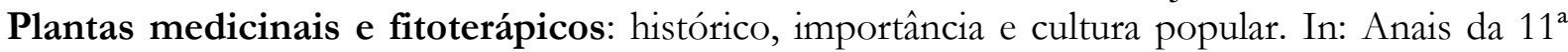
SEPEX - Semana de Ensino, Pesquisa e Extensão da UFSC, Florianópolis, 2012.

.; BRAVIANO, G. A influência da cultura popular no uso de plantas medicinais por estudantes da universidade federal de Santa Catarina. In: Anais do ENAPET: Encontro Nacional de Grupos PET, Recife, 2013. 
Sucesso e fracasso dos bolsistas do Programa Conexões de Saberes da UFSC

SILVA, V. C.; SARVACINSKI, F.; MACHADO, V.; BRAVIANO, G. A influência da cultura popular no tratamento de estresse com plantas medicinais. In: Anais da $10^{\mathrm{a}}$ SEPEX Semana de Ensino, Pesquisa e Extensão da UFSC, Florianópolis, 2011.

SOUZA, E. R.; COSTA, T. S.; DIAS, M. O.; BRAVIANO, G. Ações afirmativas sob a ótica dos direitos humanos. In: Anais da $10^{a}$ SEPEX - Semana de Ensino, Pesquisa e Extensão da UFSC, Florianópolis, 2011.

WEISS, E.; VOGES, K.; PADILHA, R.; BRAVIANO, G. Características geradoras de exclusão. In: Anais do ENAPET: Encontro Nacional de Grupos PET, Recife, 2013. 